\title{
Simulated climate change increases juvenile growth in a Critically Endangered tortoise
}

\author{
Nicola J. Mitchell ${ }^{1, *}$, Tara V. Jones ${ }^{1}$, Gerald Kuchling ${ }^{2}$ \\ ${ }^{1}$ School of Animal Biology, The University of Western Australia, Crawley, Western Australia 6009, Australia \\ ${ }^{2}$ Department of Environment and Conservation, Swan Coastal District, 5 Dundebar Rd, Wanneroo, Western Australia 6065, \\ Australia
}

\begin{abstract}
Climate change can affect the availability of transient habitats upon which many species depend for growth and reproduction. In south-western Western Australia, declines in winter rainfall since the 1970s have shortened the hydroperiod of ephemeral swamps occupied by the Critically Endangered western swamp tortoise Pseudemydura umbrina reducing the length of the growing period of hatchlings and juveniles. Here, we tested whether the warmer water temperatures expected under global climate change could compensate for a shorter growing season. We increased pond temperatures of captive hatchlings and juveniles ( 1 and $2 \mathrm{yr}$ old) by 1 to $2^{\circ} \mathrm{C}$, and showed that growth rates and rates of food intake increased with temperature, with hatchlings in heated ponds increasing their mass by an additional 78\% compared to hatchlings in unheated ponds. Hatchlings had a growth rate 8 times greater than that of juveniles. With an unlimited food supply, we predict that wild hatchlings will reach the critical mass (about $18 \mathrm{~g}$ ) necessary to survive their first aestivation period at least 1 mo earlier under projected climate change by 2050 . However, because shorter hydroperiods translate to longer periods for dry-season aestivation, small tortoises that have allocated all their energy to growth will be especially vulnerable to depletion of energy stores during aestivation.
\end{abstract}

KEY WORDS: Climate change $\cdot$ Hydroperiod $\cdot$ Growth $\cdot$ Tortoise $\cdot$ Pseudemydura

\section{INTRODUCTION}

Regional changes in climate are potentially among the largest threats facing modern species, with many species at risk of extinction (Hughes 2003, Parmesan \& Yohe 2003, Williams et al. 2003, Thomas et al. 2004, 2006, Walther et al. 2005). Ectothermic species such as reptiles will be especially affected by changes in temperature due to the direct influence of temperature on physiological processes (Schmidt-Nielsen 1975, Parmenter 1980, Przeslawski et al. 2008, Tewksbury et al. 2008). Higher temperatures increase ectotherm growth rates and decrease developmental periods (e.g. Elliott 1976, Reid et al. 1995, Hutchinson \& Hawkins 2004), but individuals may also behaviourally thermoregulate to lower their body temperature in order to moderate some of these physiological effects (Kearney et al. 2009). For species that are threatened by other processes, understanding how climate change will interact with or magnify existing threats will be essential to their effective management.

One species already impacted by climate change is the Critically Endangered western swamp tortoise Pseudemydura umbrina from south-western Western Australia. P. umbrina has an unusual biology for a reptile that occurs in a Mediterranean climate; it is active and feeds and breeds in the cooler months of the year in ephemeral swamps (Burbidge et al. 2010). Swamps typically fill in winter when low water temperatures limit energy acquisition and growth (King et al. 1998). Swamps dry out in late spring, and adult 
tortoises leave the swamps when water temperatures consistently exceed $28^{\circ} \mathrm{C}$ and move to aestivation sites in burrows or under vegetation, where they remain until the following wet season (Burbidge 1981). Eggs develop in terrestrial nests, and hatchling sex does not appear to be influenced by incubation temperature. The most immediate threat from climate change is diminishing rainfall that will reduce the period of time that the swamps hold water. South-western Australia has already experienced a marked decline in rainfall since the 1970s (Smith 2004), and future projections indicate that the region will become warmer and drier, with rainfall predicted to decrease by up to $60 \%$ by the year 2070 (Bates et al. 2008). The drying climate has led to management interventions such as bunding swamps to increase water levels, providing plastic-lined refuge ponds and pumping bore water into swamps to provide tortoises with standing water for as long as possible (Burbidge et al. 2010).

The projected changes in regional climate suggest that Pseudemydura umbrina will continue to be exposed to shorter wet seasons (CSIRO 2007), but water temperatures will be warmer. Shorter wet seasons are likely to reduce hydroperiods (the number of days of standing water), meaning that hatchlings may not have a sufficiently long growing period to reach a body size that would allow them to survive their first aestivation (approximately $18 \mathrm{~g}$; G. Kuchling unpubl. data). This critical size threshold may increase under a warmer climate if the aestivation period is further prolonged. However, it is also possible that because adult tortoises increase their body mass faster when they spend more time in warmer water (King et al. 1998), hatchlings may also be able to sustain increased growth rates in warmer water, and reach a critical mass for survival of aestivation under a shorter hydroperiod.

In this study, we examined how growth rates, food intake and foraging behaviour of hatchling and juvenile Pseudemydura umbrina varied with water temperature during winter and early spring, with the goal of predicting how wild hatchlings would fare under a shift to a warmer and drier climate. Because low environmental temperatures constrain feeding and growth in tortoises (Ligon \& Lovern 2009), we hypothesised that rates of growth and food intake in $P$. umbrina would increase with increasing temperature. Secondly, due to the importance of energy acquisition in hatchlings, we predicted that hatchlings would have a greater growth rate than juveniles. Finally, we used growth functions derived from our data on captive individuals to predict growth tra- jectories under current field temperatures, and under medium emissions global change scenarios for southwestern Australia.

\section{MATERIALS AND METHODS}

\section{Study animals and housing}

Twenty-six hatchling tortoises and 34 juvenile (1 to 2 yr old) Pseudemydura umbrina were studied in a captive breeding population maintained at the Perth Zoo. Most tortoises had hatched in captivity following incubation at either 24 or $29^{\circ} \mathrm{C}$ (standard husbandry practices; Kuchling 2006), and had originated from wild or captive-bred parents. However, 7 of the 1 yr olds originated from 2 clutches incubated naturally in the breeding enclosures, while 4 of the $2 \mathrm{yr}$ olds had been obtained from the wild as eggs, then incubated in captivity at $24^{\circ} \mathrm{C}$. The sex of $P$. umbrina can only be determined when individuals reach 180 to $200 \mathrm{~g}$ (6 to $15 \mathrm{yr}$ in captivity); hence in this study of hatchlings and juveniles, the sex of individuals was unknown.

Upon hatching, or after a period of obligatory aestivation (juveniles), tortoises were introduced into growing ponds. Tortoises were allocated to ponds according to their size and incubation history in an attempt to create a similar composition of animals in each pond. The ponds for hatchlings were of 2 sizes: 2 were $2 \times 1.1 \mathrm{~m}$ and 4 were $2.6 \times 1.1 \mathrm{~m}$, with a maximum depth of approximately $0.3 \mathrm{~m}$. Growing ponds for juveniles were also of 2 sizes: 2 were approximately $3.4 \times 1.1 \mathrm{~m}$, with a maximum depth of $0.4 \mathrm{~m}$, and 4 were $3.8 \times 1.1 \mathrm{~m}$, with a maximum depth of $0.32 \mathrm{~m}$. All ponds were lined with black polyethylene plastic and river sand (hatchling ponds) or gravel (juvenile ponds), and contained enrichment items including logs, PVC pipe shelters and shade cloth strips (Kuchling 2006). The 1 yr old juveniles $(n=13)$ were divided between 2 ponds, and the 2 yr olds $(\mathrm{n}=$ 21) were allocated to the remaining 4 ponds.

Temperature fluctuations are important for ecological validity, as growth rates of many ectotherms increase significantly with diel temperature fluctuation (Needham 1964, Dong 2006). Hence rather than create constant water temperatures by pumping thermostated water into ponds, we warmed 3 of the 6 ponds in each group using Jager 200W aquarium heaters. The heaters ( 1 in each hatchling pond and 2 in each juvenile pond) were contained within PVC covers, and the same number of PVC covers were placed in the unheated ponds to serve as procedural 
controls. Due to differences in hatching dates, some hatchlings were several months old when heating began on 17 June 2009, while other individuals that hatched after this date were placed in heated ponds upon hatching. Heating of juvenile ponds also commenced on 17 June, $21 \mathrm{~d}$ after juveniles were removed from aestivation and allocated to ponds. Heating experiments concluded on 20 September 2009.

\section{Measurement of water temperatures and tortoise temperatures}

Water and air temperatures were measured every 20 min using small temperature loggers (DS1921G Thermocron iButtons, Maxim). All loggers were coated with a black silicon glazing agent to protect them from moisture. Tortoises were too small to carry iButtons, so we used life-sized, water-filled copper models (painted matt black to match carapace colour reflection and absorbance) fitted with internal temperature loggers to approximate the core temperatures of tortoises. Two models were deployed in each pond; one under cover in the deepest part of the pond, and another in a shallow, relatively open area, to reflect differences in the thermal microclimates available to tortoises.

To determine the relationships between internal and surface temperatures of tortoises, and between live tortoises and models, we measured surface temperatures with an infra-red thermometer (ZyTemp TN425LC) within the same 5 min period. A tortoise's position was noted (i.e. under cover, in open in shallow or deep water), then it was captured, and its temperature immediately measured out of the water with the infra-red thermometer. The cloacal (internal) temperature of juveniles was also measured, using a thermocouple and digital thermometer. This process was conducted on 6 different days for hatchlings, and on 4 different days for juveniles, over a period of $6 \mathrm{wk}$.

\section{Growth measurements}

Hatchling and juvenile growth was assessed using a variety of measures: body mass, carapace length, carapace width, plastron length and carapace height. All animals were measured between 09:00 and 11:00 $\mathrm{h}$ on the same day of each week and were fed afterward. Hatchlings were measured weekly, and juveniles were measured fortnightly. Specific growth rates (SGRs, expressed as percentages) were calculated from the formula:

$$
\begin{gathered}
\mathrm{SGR}=\left(\operatorname{lnMass}_{\mathrm{N}}-\operatorname{lnMass} \operatorname{Man}_{\mathrm{N}-1}\right) / \\
\left(\text { Time }_{\mathrm{N}}-\text { Time }_{\mathrm{N}-1}\right) \times 100
\end{gathered}
$$

where $\mathrm{N}$ is the mass recorded at time $\mathrm{N}$, and $\mathrm{N}-1$ is the mass recorded on the previous measurement date (Andrews 1982).

\section{Measurement of feeding activity}

All tortoises were fed in excess to reduce competition for food and to ensure that food availability did not restrict growth rates. Hatchlings were fed live food (brine shrimp, blood worms and mosquito larvae), and food intake could not be quantified. Juveniles were fed cubes of 'tortoise pudding' (minced skinned rat, beef heart, marron or yabbies [both crustaceans], fish, egg yolk, gelatine, herpetavite and calcium carbonate) 3 times a day $(0: 900,12: 00$ and 15:00 h), and the amount of food consumed over each period was recorded. We changed the feeding regime (amount at any feeding time) at several points during the experiment in an attempt to provide food when the tortoises were most likely to eat it.

\section{Observations of basking behaviour}

We recorded tortoise behaviours on randomly allocated, dry days, up to $1 \mathrm{~d} \mathrm{wk}^{-1}$ using wireless security cameras (Swann). The 2 adjacent 1 yr old ponds (1 heated, 1 unheated) were used for recordings of juveniles, and 4 hatchling ponds (2 heated, 2 unheated) were used for recordings of juveniles. Video recordings were made between approximately 08:30 and 15:45 $\mathrm{h}$, alternating between heated and unheated ponds at $4 \mathrm{~s}$ intervals and stored on a laptop computer. The video footage was later analysed, and basking behaviour was scored if a tortoise's carapace was at the surface or out of the water for over $2 \mathrm{~min}$.

\section{Statistical analysis}

Data were analysed using JMP 8.0 (SAS Institute) and StatistiXL (Microsoft). One hatchling died 2 mo into the study, so data for this individual were only included in analyses of SGR relative to age. All data sets met assumptions for normality and homogeneity of slopes unless otherwise stated, in which case a non-parametric test was used. 
Hatchling SGRs were analysed with analysis of covariance (ANCOVA) using the Restricted Maximum Likelihood (REML) method. The potential covariates of hatching weight, pre-heating SGR and age (days since hatching) were analysed in a step-wise fashion for model fitting. Only age accounted for variation in the model and was thereafter included in analysis. Treatment (heated or unheated) and incubation temperature were included as fixed factors, while pond was included as a random factor nested within treatment. The covariate age (days), and the associated interaction effects, were included as independent variables. Interaction effects were removed from the highest to lowest order if they were not significant $(\mathrm{p}>0.25)$.

An identical ANCOVA was constructed for juvenile SGR. Age measured in days accounted for more variation in the model than age in years and was therefore used as the covariate. The exact age of $1 \mathrm{yr}$ olds that were incubated naturally was unknown, so we estimated the age of these individuals as the average age of $2 \mathrm{yr}$ olds minus $365 \mathrm{~d}$.

\section{Food intake}

An ANCOVA was performed to determine the effect of food intake and water temperature on the SGR of juveniles, using data recorded over a $12 \mathrm{wk}$ period. Food intake for each pond was calculated as the average daily intake over each 2 wk period, divided by the number of tortoises in each pond. Average water temperature for each $2 \mathrm{wk}$ period was calculated for each pond, but if water temperature records were unavailable due to logger failure, water temperature was estimated from the temperature of the copper model in shallow water, which was $0.12^{\circ} \mathrm{C}$ cooler than the surrounding water $(n=273)$.

\section{Model of hatchling growth}

We tested whether a growth model derived from pooled growth data could accurately predict the mass of an individual captive tortoise on a particular date. First, we averaged the water temperatures recorded in each pond (heated and unheated) for each week of the study. In the few cases where the water temperature loggers had malfunctioned, we estimated water temperatures from the internal temperatures of the shallow copper models. Hatchling SGR and age (weeks) were then calculated for individual tortoises in each pond.
To determine whether hatchling SGR varied with water temperature, we collated the average weekly water temperatures for each hatchling pond and the associated SGR and age data. These data were then ranked by water temperature (range: $15-20^{\circ} \mathrm{C}$ ) and grouped into $1^{\circ} \mathrm{C}$ increments (e.g. $15-15.99^{\circ} \mathrm{C}$ ). Hatchling SGRs and ages were plotted for each $1^{\circ} \mathrm{C}$ increment to produce 5 separate regressions. We used ANCOVA with SGR as the independent variable and age (weeks) as the covariate to assess for differences in slopes, and hence to determine whether hatchling SGR varied with water temperature.

We used these linear relationships between hatchling SGR and age (see Table 2) to reconstruct the growth trajectories of 12 captive hatchlings, in accordance with the changes in water temperature of the particular pond in which each individual resided. The mass of an individual in the first week of the study was used as the initial mass, and thereafter growth (mass change in $\mathrm{g}$ ) was calculated from the relationships between age and SGR (see Table 2) based on the average water temperature experienced by an individual in each week of the study. We then compared the actual and modelled masses of hatchlings at the end of the study using a 2-tailed paired $t$-test.

Having demonstrated that growth rates were predictable under ad libitum food (see Results) we used the same methodology to assess how the warmer water temperatures expected under climate change would affect the growth of hatchlings in the wild. Ellen Brook Nature Reserve (EBNR) hosts the only wild breeding population of Pseudemydura umbrina (Burbidge et al. 2010), and climate data are collected every $15 \mathrm{~min}$ at an automated weather station. Water temperatures are recorded in deeper water (up to $0.6 \mathrm{~m}$ below the surface) in a section of swamp that typically holds water for the longest period. These temperatures would be representative of typical water temperatures at ENBR due to wind mixing and other processes that moderate thermal stratification in shallow water (Imberger \& Hamblin 1982). Water temperatures were averaged for each day from 19 June 2009 (the date the swamp began to fill) until 20 November 2009 (the date the swamp dried) to form a basis for a model under the current climate. We also considered how much growth could have occurred under a range of shorter hydroperiods, based on hydroperiod frequencies at EBNR recorded since 1972 (see Fig. 3).

Three other water temperature scenarios were constructed based on a range of likely air tempera- 
ture increases by 2050 modelled under medium-level greenhouse gas emissions (CSIRO 2007). The temperatures of surface water and shallow water bodies closely reflect air temperatures (Livingstone \& Lotter 1998), hence we assumed that water temperatures would increase by the same increment as air temperatures. We added $0.6^{\circ} \mathrm{C}$ (winter) and $1^{\circ} \mathrm{C}$ (spring) to current water temperatures for a minimum warming projection, $1^{\circ} \mathrm{C}$ (winter) and $1.5^{\circ} \mathrm{C}$ (spring) for a medium warming projection and $1.5^{\circ} \mathrm{C}$ (winter) and $2^{\circ} \mathrm{C}$ (spring) for a maximum warming projection. We further assumed that body temperatures of hatchlings would be $0.5^{\circ} \mathrm{C}$ warmer than water temperatures, consistent with empirical data collected in this study (see Table 1)

Hatchling SGRs were unknown for temperatures below $15^{\circ} \mathrm{C}$ and above $20^{\circ} \mathrm{C}$, whereas water temperatures at EBNR frequently exceeded these bounds. Hence SGRs were estimated at low $\left(<15^{\circ} \mathrm{C}\right)$ and high $\left(>20^{\circ} \mathrm{C}\right)$ water temperatures using a temperature coefficient, or $\mathrm{Q}_{10}$ (Bennet 1988) calculated for ages 1 to 23 wk using the $15-16^{\circ} \mathrm{C}$ and $19-20^{\circ} \mathrm{C}$ SGRs (see Table 2). The $\mathrm{Q}_{10}$ ranged from 12.84 for $1 \mathrm{wk}$ old hatchlings to 2.04 for $23 \mathrm{wk}$ old hatchlings, indicating the much greater influence of temperature on SGRs in the earlier age classes. The initial mass of a wild hatchling was standardised to $6 \mathrm{~g}$ (Burbidge 1967), and we assumed that hatchling growth commenced once standing water was available.

\section{RESULTS}

\section{Water and tortoise temperatures}

The aquarium heaters raised water temperatures by approximately 1 to $2^{\circ} \mathrm{C}$ above the temperature of the unheated ponds, and so reflected the winter/spring air temperature increase predicted by 2050 in south-western Australia (CSIRO 2007). The mean daily temperature from June to September of heated hatchling ponds was $17.9^{\circ} \mathrm{C}$ (range: 15.9-20.6) compared to $17.0^{\circ} \mathrm{C}$ in unheated ponds (range: 14.1-19.8). The mean daily temperature of heated juvenile ponds was $18.0^{\circ} \mathrm{C}$ (range: $14.1-20.6$ ) and $15.7^{\circ} \mathrm{C}$ in unheated ponds (range: $12.8-18.7^{\circ} \mathrm{C}$ ).

Water temperatures, tortoise temperatures and copper model temperatures (Table 1) were significantly different for hatchlings (analysis of variance, ANOVA; $F_{5,89}=3.26, \mathrm{p}=0.01$ ), but not for juveniles $\left(\right.$ ANOVA $\left._{i} F_{6,104}=2.14, \mathrm{p}=0.06\right)$. Post hoc tests showed that the internal temperature of the hatchling copper model positioned in deep water was sig-
Table 1. Pseudemydura umbrina. Comparison of water, tortoise and copper model temperatures $\left({ }^{\circ} \mathrm{C}\right)$ for hatchlings and juveniles. $\mathrm{n}=15$ for all measurements

\begin{tabular}{|lcc|}
\hline Group & Mean & SE \\
\hline Hatchlings & & \\
Water & 17.70 & 0.43 \\
Carapace & 19.32 & 0.80 \\
Shallow copper model internal & 18.20 & 0.47 \\
Deep copper model internal & 16.53 & 0.29 \\
Shallow copper model surface & 19.39 & 0.82 \\
Deep copper model surface & 19.09 & 0.72 \\
Juveniles & & \\
Water & 17.70 & 0.41 \\
Cloaca & 18.36 & 0.38 \\
Carapace & 17.76 & 0.55 \\
Shallow copper model internal & 18.13 & 0.42 \\
Deep copper model internal & 17.07 & 0.36 \\
Shallow copper model surface & 18.48 & 0.43 \\
Deep copper model surface & 16.81 & 0.46 \\
\hline
\end{tabular}

nificantly cooler than the carapace temperature of hatchlings ( $p=0.025)$ and cooler than the surface temperature of the copper model positioned in shallow water $(\mathrm{p}=0.02)$.

\section{Growth}

All size measurements were significantly correlated, hence mass was the only size measurement used to assess differences in growth rates. Irrespective of water temperature, hatchling SGRs (mean: 6.71) were significantly greater than juvenile SGRs (mean: 0.82) over a $15 \mathrm{wk}$ period (ANOVA, $F_{1,58}=$ 223.70, $\mathrm{p}<0.001)$. After controlling for age, heating pond water significantly increased the SGR of hatchlings $\left(F_{1,4.1}=10.92, \mathrm{p}=0.029\right)$ and juveniles $\left(F_{1,3.2}=\right.$ 10.19, $\mathrm{p}=0.045$; Fig. 1). In contrast, a hatchling's incubation regime did not significantly affect SGR in either age class (hatchlings: $F_{1,18.9}=1.99, \mathrm{p}=0.175$; juveniles: $F_{2,26.9}=2.40, \mathrm{p}=0.110$ ). Hatchlings in the heated ponds were significantly larger than those in the unheated ponds after $6 \mathrm{wk}$ of heating (ANCOVA $F_{2,24}=28.52, \mathrm{p}<0.001$; effect tests: heating $F_{1,1}=$ 4.66, $\mathrm{p}=0.042$, age [weeks] $F_{1,1}=56.98, \mathrm{p}<0.001$ ).

Hatchling SGR and age (weeks) were significantly correlated for all temperature ranges except for $15-16^{\circ} \mathrm{C}$, with a significant difference between slopes (ANCOVA, $F_{4,397}=397, \mathrm{p}=0.001$ ). Tukey's post hoc slope comparison revealed that the $15-16^{\circ} \mathrm{C}$ slope significantly differed from the $19-20^{\circ} \mathrm{C}$ slope, and the $16-17^{\circ} \mathrm{C}$ slope significantly differed from the $17-18^{\circ} \mathrm{C}, 18-19^{\circ} \mathrm{C}$ and $19-20^{\circ} \mathrm{C}$ slopes (Table 2). 

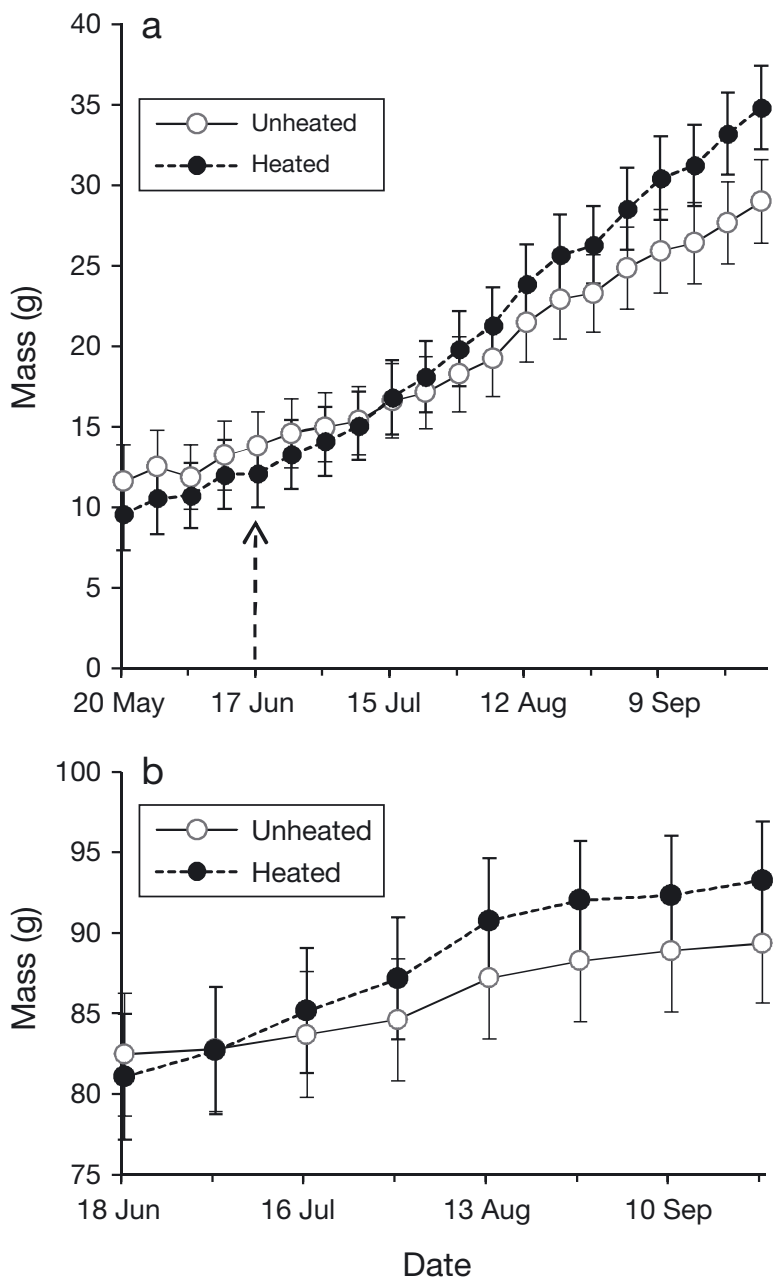

Fig. 1. Pseudemydura umbrina. Average mass \pm SE for (a) hatchlings and (b) juveniles in unheated and heated ponds. Heating for (a) and (b) began on 17 June 2009 (dashed arrow in a)

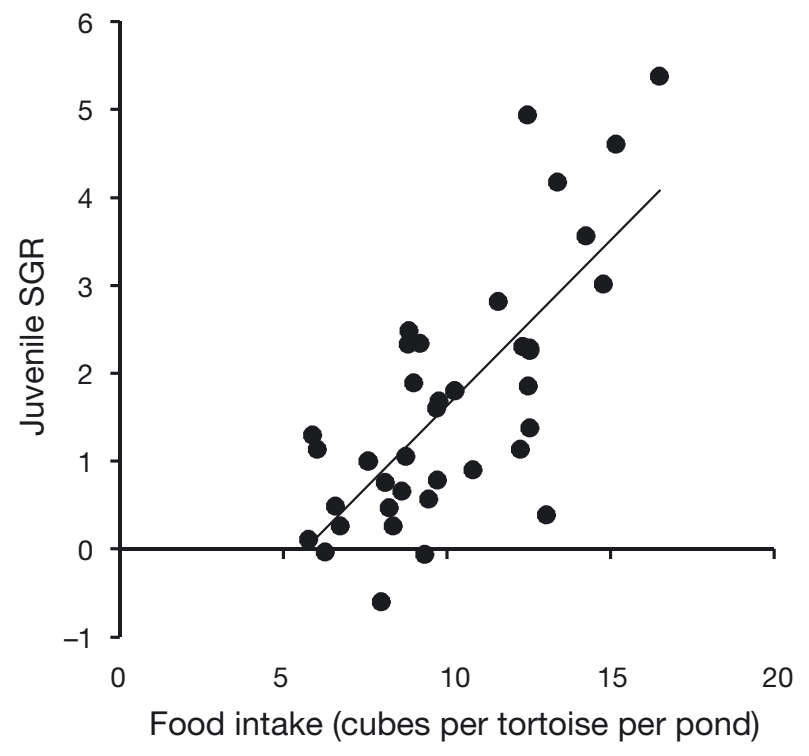

Fig. 2. Pseudemydura umbrina. Juvenile specific growth rate (SGR) as a function of food intake (cubes per tortoise per pond) $\left(\mathrm{r}^{2}=0.63, F_{1,34}=56.63, \mathrm{p}<0.001\right)$

more than those in unheated ponds at each time period (Table 3). This difference was most pronounced before 15:00 $\mathrm{h}$, before the ponds had reached their daily maximum temperature. Observations of the feeding behaviour of hatchlings suggested that hatchlings fed at all times of day, with a peak in feeding activity around 14:00 to $16: 00 \mathrm{~h}$.

Hatchlings were observed basking 11 times, with 9 observations in unheated ponds, where most hatchlings sat out of the water at the edge of the pond. No juveniles were observed basking.

\section{Growth model}

The estimated masses of captive-reared hatchlings (mean: $24.1 \mathrm{~g}$ ) were not significantly different from actual masses (mean: $25.3 \mathrm{~g} ; t=-1.06, \mathrm{p}=0.31$, $\mathrm{df}=$ cant effect on juvenile SGR (ANCOVA $F_{6,39}=8.21$ $\mathrm{p}<0.001)$. Effect tests showed that when controlling for food intake $\left(F_{1,1}=16.31, \mathrm{p}<0.001\right)$, water temperature did not account for the change in $\operatorname{SGR}\left(F_{5,5}=6.90, \mathrm{p}=\right.$ 0.49). The water temperature and food intake of juvenile tortoises were significantly correlated (Fig. 2).

Food intake was compared between juveniles in unheated and heated ponds for each time period (morning: 09:00-12:00 h, afternoon: 12:00-15:00 h and overnight: 15:00-09:00 h). Juveniles in heated ponds ate significantly

Table 2. Pseudemydura umbrina. Specific growth rate (SGR) related to age (a) in weeks for each temperature category. Statistically significant at ${ }^{*} \mathrm{p}<0.05$,

$$
{ }^{* *} \mathrm{p}<0.001
$$

\begin{tabular}{|lccccc|}
\hline $\begin{array}{l}\text { Temperature } \\
\text { range }\left({ }^{\circ} \mathrm{C}\right)\end{array}$ & $\begin{array}{c}\text { Regression } \\
\text { SGR }\end{array}$ & $\mathrm{r}^{2}$ & $F$ & $\mathrm{df}$ & $\mathrm{p}$ \\
\hline $15-16$ & $-0.1192 a+6.7018$ & 0.060 & 1.40 & 1,22 & 0.249 \\
$16-17$ & $-0.1791 a+8.1404$ & 0.151 & 14.55 & 1,82 & $<0.001^{* *}$ \\
$17-18$ & $-0.3915 a+12.324$ & 0.306 & 80.05 & 1,182 & $<0.001^{* *}$ \\
$18-19$ & $-0.4158 a+14.658$ & 0.393 & 61.43 & 1,95 & $<0.001^{* *}$ \\
$19-20$ & $-0.5919 a+18.879$ & 0.516 & 12.81 & 1,12 & $0.004^{*}$ \\
\hline
\end{tabular}


Table 3. Pseudemydura umbrina. Wilcoxon paired-sample tests comparing juvenile food intake in unheated and heated ponds for each time period. am: food consumed between 09:00 and 12:00 $\mathrm{h}_{\text {; }} \mathrm{pm}$ : food consumed between 12:00 and 15:00 $\mathrm{h}$; evening: food consumed after 15:00 $\mathrm{h}$ and before 09:00 $\mathrm{h}$ the following day. $\mathrm{n}=317$ for all measurements

\begin{tabular}{|lcccc|}
\hline Pond & Median & Sum & $z$ & $\mathrm{p}$ (2-tailed) \\
\hline Unheated (am) & 0.4 & 300 & & \\
Heated (am) & 1.6 & 559 & 9.85 & $<0.001$ \\
Unheated (pm) & 0.6 & 408 & & \\
Heated (pm) & 2.5 & 770 & 10.27 & $<0.001$ \\
Unheated (evening) & 6.4 & 1984 & & \\
Heated (evening) & 6.4 & 2177 & 6.46 & $<0.001$ \\
\hline
\end{tabular}

11), indicating that growth rates with ad libitum food were predictable. The models of growth trajectories in the wild under current and predicted water temperatures suggested that a 5 mo hydroperiod would allow hatchlings to increase in mass from $6 \mathrm{~g}$ at hatching to $21.1 \mathrm{~g}$ at current water temperatures, and to $25.9,29.8$ and $34.6 \mathrm{~g}$ at water temperatures predicted by 2050 (Fig. 3).

\section{DISCUSSION}

Growth rates of Pseudemydura umbrina in winter and early spring increase substantially with a small increase in temperature (an increase of only $0.9^{\circ} \mathrm{C}$ in hatchlings) when provided with ad libitum food. Hatchlings were significantly larger after just $6 \mathrm{wk}$ of heating, and this difference increased over time (Fig. 1). These findings support a previous field study of adult $P$. umbrina, where growth rates were greater in individuals that exploited warmer microclimates (King et al. 1998), as well as studies of other chelonians (Chrysemys s. scripta and Chelydra serpentina) that grew faster in heated ponds (Gibbons 1970, Gibbons et al. 1981). The thermal environment prior to hatching had no effect on the growth rate of $P$. umbrina, similar to a study of the turtle Macrochelys temminckii (Ligon \& Lovern 2009), but unlike some other studies of reptiles (Rhen \& Lang 1999, Nelson et al. 2004) where the thermal environment during embryogenesis had significant effects on posthatching growth rates.

Increased food intake was the predominant cause of more rapid growth of juveniles, as temperature did not have a significant effect on juvenile SGR after controlling for food intake. Given that ad libitum food was provided to hatchlings, it is likely that hatchlings also responded to warmer water temperatures by

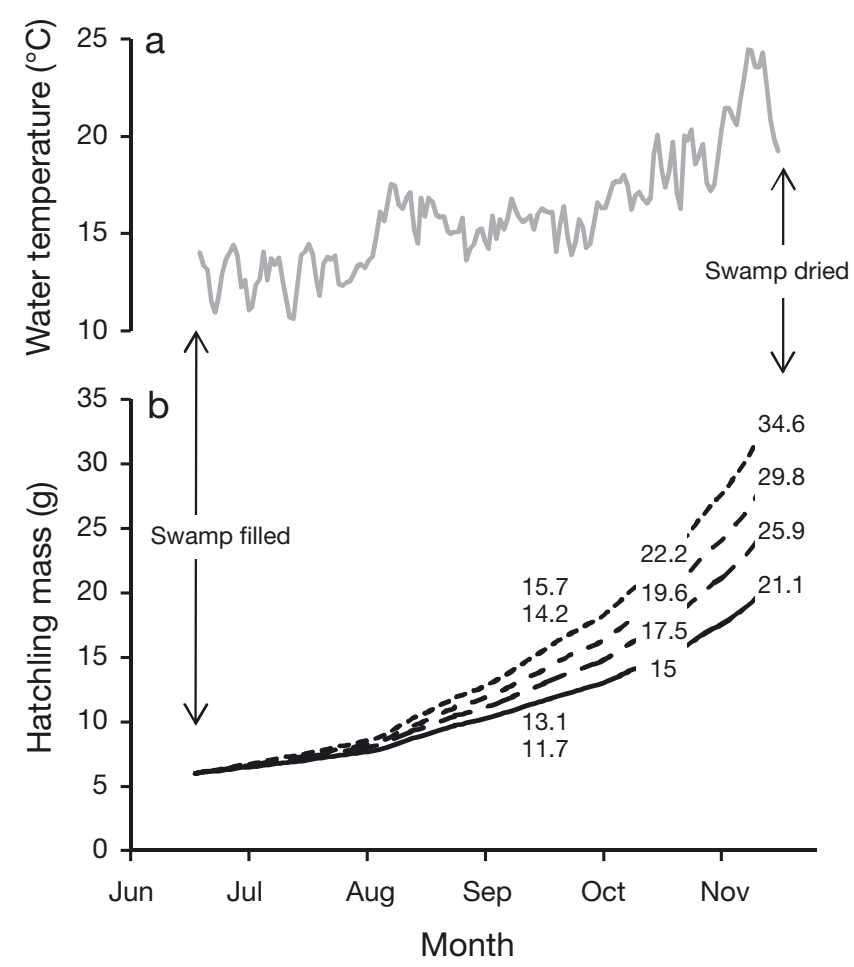

Fig. 3. Pseudemydura umbrina. (a) Water temperatures at Ellen Brook Nature Reserve, Western Australia and (b) hatchling growth trajectories modelled on the 2009 water temperatures and hydroperiod (solid line), and on water temperatures predicted by 2050 with either a high (10th percentile: minimum warming) (long dashes), medium (50th percentile: medium warming) (medium dashes) or low (90th percentile: maximum warming) (short dashes) confidence of occurring under medium level emissions. Tick marks indicate the start of each month. Values overlaid onto each trajectory indicate hatchling masses at hydroperiods of 3, 4 and 5 mo. Since 1972, $3 \%$ of hydroperiods have been $<3$ mo, $14 \%$ have been 3 to $4 \mathrm{mo}, 22 \%$ have been 4 to $5 \mathrm{mo}, 32 \%$ have been 5 to 6 mo, and $29 \%$ have exceeded 6 mo

increasing their rate of feeding. Increased growth rates at higher temperatures may be due to increased digestion efficiency (Needham 1964, Laudien 1973, Bennett \& Dawson 1976) and/or to increased potential activity time (Sinervo \& Adolph 1989, Wilkinson \& Rhodes 1997). Our study suggested that water temperature did constrain activity and feeding opportunities: tortoises preferred to feed after 16:00 $\mathrm{h}$ when water temperatures were highest, but when tortoises in heated ponds were not sated overnight, they were also able to feed in the morning and afternoon. However, tortoises in unheated ponds did not feed in the morning unless it was a warm day, even if food was limited overnight (T. Jones pers. obs.). Hence an increased demand for food due to increased metabolic costs at higher temperatures could be accom- 
modated by an increased potential activity time in Pseudemydura umbrina (sensu Kearney et al. 2009).

Only 1 hatchling in the study did not reach the critical mass of $18 \mathrm{~g}$ by the end of September. This tortoise was the second last to hatch, in the middle of June 2009, but even so had reached $16 \mathrm{~g}$ by the end of the study. Older hatchlings (hatching in March to April) grew at comparatively warmer temperatures when they were young relative to those that hatched in May to June, and this 'head start' meant they were able to reach weights of up to $57 \mathrm{~g}$ by the end of the study. The situation for tortoises that hatch early in captivity may be different from those that hatch in the wild, as wild hatchlings may have to wait weeks until the swamps fill and must rely on their reserve of stored yolk to survive the intervening dry period. Individuals that hatch early are also more prone to desiccation and predation relative to individuals that emerge when the swamps contain water.

Although growth rates were higher in Pseudemydura umbrina hatchlings than in juveniles, the annual body mass increment of hatchlings and juveniles appears to be relatively constant. For age classes corresponding to this study, Burbidge (1967) calculated (assuming 6 mo of standing water) growth increments for $P$. umbrina at Twin Swamps Nature Reserve as follows: a body mass of $6 \mathrm{~g}$ at age 0 (hatching), $50 \mathrm{~g}$ at age $0.5 \mathrm{yr}, 95 \mathrm{~g}$ at age $1.5 \mathrm{yr}$, and $135 \mathrm{~g}$ at age $2.5 \mathrm{yr}$. Twin Swamps provided good habitat for $P$. umbrina during the mid-1960s, but due to declining rainfall, this population was close to extinction by the 1980s (Burbidge et al. 2010).

\section{Model of hatchling growth under current and under future climates}

Water temperatures and copper model temperatures are both good indicators of hatchling and juvenile body temperatures in Pseudemydura umbrina (Table 1), hence water temperatures at EBNR provided a useful basis for predicting the growth of wild hatchlings. Our models suggested that hatchlings growing in warmer water bodies under future climates would be between 4.6 and $13.9 \mathrm{~g}$ heavier after a 5 mo hydroperiod than wild hatchlings growing under current conditions. The model based on the most likely scenario of increasing temperature (1 to $1.5^{\circ} \mathrm{C}$ increase in air temperatures) showed hatchlings exceeding the critical mass of $18 \mathrm{~g}$ by midOctober, provided that food is unlimited (Fig. 3). However, our growth trajectories are conservative because they do not allow for basking behaviours that would periodically elevate the body temperatures of hatchlings above water temperatures. Wild tortoises can exploit warmer microclimates in very shallow water where during sunny days temperatures are at least $5^{\circ} \mathrm{C}$ higher than in deeper water (Burbidge 1967, King et al. 1998). Behavioural thermoregulation would elevate body temperatures and promote concomitant increases in feeding and growth rates with unlimited food.

The critical mass of $18 \mathrm{~g}$ indicated in Fig. 3 corresponds to the minimal hatchling body mass at the end of the growing season below which no Pseudemydura umbrina has ever been recaptured at EBNR (Burbidge 1981, G. Kuchling unpubl.), but is certainly not the optimal mass for survival. Modelling a medium warming scenario showed that an average hatchling would reach this mass by early October, and in years of good rainfall, hatchlings could continue to grow until December, at which time the water usually evaporates. Notably, if shorter hydroperiods occur due to declining rainfall, hatchlings should still reach $18 \mathrm{~g}$ before the swamps dry the due to their faster growth rates. However, this mass threshold may be greater under an extended period of aestivation in potentially drier and warmer soils, and additional monitoring of wild hatchlings will be necessary to refine it. Regional climate change models predict exceptionally low soilmoisture years on average once every 6 yr by 2030 (Bates et al. 2008, Hennessy et al. 2008), in which case larger hatchlings that are able to store more bladder water and that have smaller surface area to volume ratios will be more resilient to desiccation in aestivation sites than smaller hatchlings.

Even though Pseudemydura umbrina may be able to maintain increased growth rates under the water temperatures predicted by climate change, individuals may not reach sexual maturity earlier, because if the time for feeding and growth is reduced due to a reduced hydroperiod, then overall growth per season may remain constant or decline despite increased growth rates. From growth rings, Burbidge (1967) measured and/or calculated the growth of $P$. umbrina at Twin Swamps Nature Reserve and reported that hatchlings reached $17.1 \mathrm{~g}$ with a hydroperiod of $3 \mathrm{mo}$ of standing water (1966, $\mathrm{n}=7), 45 \mathrm{~g}$ with 5.5 to $6 \mathrm{mo}$ $(1965, \mathrm{n}=14), 55 \mathrm{~g}$ with 6 to $6.5 \mathrm{mo}(1963, \mathrm{n}=3)$ and $60 \mathrm{~g}$ with 6.5 to 7 mo $(1964, \mathrm{n}=20)$, demonstrating the importance of the duration of the hydroperiod and of swamp life for annual growth.

The growth trajectories modelled in our study assumed that swamps will continue to fill in June (early winter). If the hydroperiod shifts temporally 
(i.e. begins later) then not only will growth rates be affected, but the time between hatching and entering the swamps could be significantly extended. Increases in summer temperatures will increase embryonic developmental rates and shorten the developmental period. At the completion of development, embryos aestivate inside the egg, and hatching is cued by a drop in temperature that is usually associated with autumn rainfalls and the filling of swamps (Burbidge et al. 2010). Hence shorter incubation periods combined with declining autumn rainfall would result in hatchlings having a longer period upon which to survive on yolk reserves before they have their first opportunity to feed. The current study deals with 2 significant consequences of climate change: a potential increase in water temperatures and continued shortening of hydroperiods in the remnant habitat. In addition to changes to early growth, the response of Pseudemydura umbrina might also include phenological or physiological shifts that are not considered here. We know nothing about the plasticity or heritability of thermal responses in this species, but generation times of around 15 to $20 \mathrm{yr}$ will not favour rapid evolution of thermal traits (Skelly et al. 2007). If critical thresholds or increased thermal tolerances do not evolve, then supplementing swamps with bore water to extend hydroperiods under a warmer climate could be futile if tortoises continue to exit swamps at $28^{\circ} \mathrm{C}$.

Ecosystem dynamics, such as vegetation changes and altered population cycles in aquatic prey species, are also likely to occur in future decades. Under conditions of food limitation that could potentially arise in drier years, growth rates at higher body temperatures might be constrained by increased metabolic maintenance costs. Hence determination of the metabolic cost of higher body temperatures and projections of food availability in the wild are both required to assess whether increased rates of growth could be sustained in warmer water. Other studies of ectotherms have shown that growth rates at warmer temperatures may decline if there is insufficient food to fuel increased metabolic rates (Jacobsen \& Kushlan 1989, Elliott 1994, Mehner \& Wieser 1994, Dalrymple 1996, Dockray et al. 1998). Behavioural thermoregulation can reduce metabolic costs (Kearney et al. 2009), hence the maintenance of heterogenous thermal habitats (e.g. by promoting vegetation growth and protecting swamps from fire) will be critical to buffer tortoises against the forecasted impacts of a warmer climate.
Acknowledgements. We thank staff at the Perth Zoo for their assistance and advice, in particular B. Durell, E. Trainer, H. Robertson and C. Lockley. The study was funded by the School of Animal Biology and the Faculty of Natural and Agricultural Sciences at the University of Western Australia, and the Australian Research Council (LP0990418). All experiments were conducted in accordance with institutional, national and international guidelines concerning the use of animals in research (University of Western Australia Permit 3-100-861 and Perth Zoo Permit 2009-1-30473).

\section{LITERATURE CITED}

Andrews R (1982) Patterns of growth in reptiles. In: Gans C, Pough FH (eds) Biology of the Reptilia. Vol 13. Academic Press, New York, NY, p 273-320

Bates BC, Hope P, Ryan B, Smith I, Charles S (2008) Key findings from the Indian Ocean Climate Initiative and their impact on policy development in Australia. Clim Change 89:339-354

Bennett AF (1988) Structural and functional determinates of metabolic rate. Am Zool 28: 699-708

Bennett AF, Dawson WR (1976) Metabolism. In: Gans C, Dawson WR (eds) Biology of the Reptilia. Vol 5. Academic Press, New York, NY, p 127-223

Burbidge AA (1967) The biology of south-western Australian tortoises. $\mathrm{PhD}$ dissertation, University of Western Australia, Nedlands

Burbidge AA (1981) The ecology of the western swamp tortoise Pseudemydura umbrina (Testudines: Chelidae). Aust Wildl Res 8:203-223

Burbidge AA, Kuchling G, Olejnik C, Mutter L (2010) Western swamp tortoise (Pseudemydura umbrina) recovery plan. 4th edn 2010-2015. Department of Environment and Conservation, Bentley, WA

CSIRO (Commonwealth Scientific and Industrial Research Organisation) (2007) Climate change in Australia - technical report. CSIRO, Canberra

> Dalrymple G (1996) Growth of American alligators in the Shark Valley region of Everglades National Park. Copeia 1996:212-216

> Dockray J, Morgan WE, Reid S, Wood C (1998) Responses of juvenile rainbow trout, under food limitation, to chronic low $\mathrm{pH}$ and elevated summer temperatures, alone and in combination. J Fish Biol 52:62-82

Dong Y, Dong S, Tian X, Wang F, Zhang M (2006) Effects of diel temperature fluctuations on growth, oxygen consumption and proximate body composition in the sea cucumber Apostichopus japonicus Selenka. Aquaculture 255:514-521

Elliott J (1976) The energetics of feeding, metabolism and growth of brown trout (Salmo trutta L.) in relation to body weight, water temperature and ration size. J Anim Ecol 45:923-948

Elliot JM (1994) Quantitative ecology and the brown trout. Oxford University Press, Oxford, p 286

Gibbons J (1970) Reproductive dynamics of a turtle (Pseudemys scripta) population in a reservoir receiving heated effluent from a nuclear reactor. Can J Zool 48: 881-885

Gibbons J, Semlitsch R, Greene J, Schubauer J (1981) Compromises of natural selection: variation at age of maturity of the slider turtle (Chrysemys scripta). Am Nat 117: 841-845 
Hennessy K, Fawcett R, Kirono D, Mpelasoka F and others (2008) An assessment of the impact of climate change on the nature and frequency of exceptional climatic events. CSIRO and the Bureau of Meteorology

Hughes L (2003) Climate change and Australia: trends, projections and impacts. Austral Ecol 28:423-443

> Hutchinson S, Hawkins L (2004) The relationship between temperature and the size and age of larvae and perimetamorphic stages of Pleuronectes flesus. J Fish Biol 65: 448-459

Imberger J, Hamblin PF (1982) Dynamics of lakes, reservoirs, and cooling ponds. Annu Rev Fluid Mech 14: 153-187

Jacobsen T, Kushlan J (1989) Growth dynamics in the American alligator (Alligator mississippiensis). J Zool (Lond) 219:309-328

Kearney MR, Shine R, Porter WP (2009) The potential for behavioral thermoregulation to buffer 'cold-blooded' animals against climate warming. Proc Natl Acad Sci USA 106:3835-3840

King J, Kuchling G, Bradshaw SD (1998) Thermal environment, behavior, and body condition of wild Pseudemydura umbrina (Testudines: Chelidae) during late winter and early spring. Herpetologica 54:103-112

Kuchling G (2006) An ecophysiological approach to captive breeding of the western swamp turtle Pseudemydura umbrina. In: Artner H, Farkas B, Loehr V (eds) Proc Int Turtle Tortoise Symp Vienna 2002. Edition Chimaira, Frankfurt am Main, p 196-225

Ligon DB, Lovern MB (2009) Temperature effects during early life stages of the alligator snapping turtle (Macrochelys temminckii). Chelonian Conserv Biol 8: 74-83

Livingstone DM, Lotter AF (1998) The relationship between air and water temperatures in lakes of the Swiss Plateau: a case study with paleolimnological implications. J Paleolimnol 19:181-198

- Mehner T, Wieser W (1994) Effects of temperature on allocation of metabolic energy in perch (Perca fluviatilis) fed on submaximal rations. J Fish Biol 45:1079-1086

Needham E (1964) The growth process in animals. Van Nostrand, Princeton, NJ

Nelson NJ, Thompson MB, Pledger S, Keall SN, Daugherty $\mathrm{CH}$ (2004) Egg mass determines hatchling size, and incubation temperature influences post-hatching growth, of tuatara Sphenodon punctatus. J Zool (Lond) 263:77-87

Editorial responsibility: Luca Luiselli, Rome, Italy
Parmenter R (1980) Effects of food availability and water temperature on the feeding ecology of pond sliders (Chrysemys s. scripta). Copeia 1980:503-514

> Parmesan C, Yohe G (2003) A globally coherent fingerprint of climate change impacts across natural systems. Nature 421:37-42

Przeslawski R, Ahyong S, Byrne M, Worheide G, Hutchings $P$ (2008) Beyond corals and fish: the effects of climate change on noncoral benthic invertebrates of tropical reefs. Glob Change Biol 14:2773-2795

Reid S, Dockray J, Linton T, McDonald D, Wood C (1995) Effects of a summer temperature regime representative of a global warming scenario on growth and protein synthesis in hardwater- and softwater-acclimated juvenile rainbow trout (Oncorhynchus mykiss). J Therm Biol 20:231-244

Rhen T, Lang J (1999) Temperature during embryonic and juvenile development influences growth in hatchling snapping turtles, Chelydra serpentina. J Therm Biol 24:33-41

Schmidt-Nielsen K (1975) Animal physiology, adaptation and environment. Cambridge University Press, London

Sinervo B, Adolph S (1989) Thermal sensitivity of growth rate in hatchling Sceloporus lizards: environmental, behavioral and genetic aspects. Oecologia 78:411-419

Skelly DK, Joseph LN, Possingham HP, Kealoha-Freidenburg L, Farrugia TS, Kinnison MT, Hendry AP (2007) Evolutionary responses to climate change. Conserv Biol 21:1353-1355

Smith I (2004) An assessment of recent trends in Australian rainfall. Aust Meteorol Mag 53:163-173

Tewksbury JJ, Huey RB, Deutsch CA (2008) Putting the heat on tropical animals. Science 320:1296-1297

> Thomas CD, Cameron A, Green RE, Bakkenes M and others (2004) Extinction risk from climate change. Nature 427: 145-148

Thomas CD, Franco A, Hill J (2006) Range retractions and extinction in the face of climate warming. Trends Ecol Evol 21:415-416

- Walther GR, Hughes L, Vitousek P, Stenseth N (2005) Consensus on climate change. Trends Ecol Evol 20:648-649

> Wilkinson PM, Rhodes WE (1997) Growth rates of American alligators in coastal South Carolina. J Wildl Manag 61: 397-402

Williams SE, Bolitho EE, Fox S (2003) Climate change in Australian tropical rainforests: an impending environmental catastrophe. Proc R Soc Lond B Biol Sci 270: 1887-1892

Submitted: May 20, 2011; Accepted: December 17, 2011 Proofs received from author(s): March 29, 2012 